\title{
Preparation of Room Temperature Vulcanized Silicone Rubber Foam with Excellent Flame Retardancy
}

\author{
Weiqi Luo, Zhimin Li, Haihua Luo, Yuting Liu, Guojiang Xia, Hangtian Zhu, Jiayi Zhou, \\ Ding Yu, Jianxin Zhang, Jianghang Song, Zhengzhou Duan, Yanxin Qiao $\mathbb{D}$, Jijun Tang, \\ Yuxin Wang, and Chunfeng Meng
}

School of Material Science and Engineering, Jiangsu University of Science and Technology, Zhenjiang, Jiangsu 212003, China

Correspondence should be addressed to Chunfeng Meng; mchf@just.edu.cn

Received 4 March 2021; Revised 2 April 2021; Accepted 11 May 2021; Published 21 May 2021

Academic Editor: Guosong Wu

Copyright (c) 2021 Weiqi Luo et al. This is an open access article distributed under the Creative Commons Attribution License, which permits unrestricted use, distribution, and reproduction in any medium, provided the original work is properly cited.

\begin{abstract}
To retard the spread of fire in many cases with sealing materials is significant. A series of silicone rubber foam materials were prepared with room temperature vulcanization and foaming reactions. The morphology, chemical structure, cell structure, and thermal stability were investigated and results proved that the synthesis of silicone rubber was successful in a wide range of feed ratios. The fire-retardant tests were carried out to study the fire-proof property of the composite materials, and the excellent performance showed a promising prospect for wide application in sealing materials.
\end{abstract}

\section{Introduction}

Large-scale flames can spread through the holes and gaps around the pipes, and cable trenches, when an accidental fire occurs. The runoff of fire can lead to a devastating outcome. According to the data released by the Emergency Management Department Fire Rescue Bureau of China, a total of 196,000 fire accidents were reported from January to October, in the year 2020, causing 889 deaths, 583 injuries, and direct property losses up to 2.55 billion yuan. The chance of tragedies can be minimized only with particular precaution measures. Herein, to retard the spread of fire in buildings with sealing materials is significant and life-saving.

In the field of fire-retardant materials, industrialization production is busy due to the market demand. A series of polymer-based composite materials, such as styrene butadiene rubber [1-3], natural rubber $[4,5]$, and so on are often used as fire-proof sealing materials to retard flames [6], especially in nuclear power stations, railway traffic, through-the-wall cable channels, and other fields. Generally, the composite materials are categorized into two types according to the relation between the retardant and the polymer material, which are reaction-type and additive- type [7]. In recent years, silicone rubber foam has been one of the most successful commercialized additive-type fire-proof products $[8,9]$, due to the comparatively higher thermal stability of silicones than their polymer counterparts, the shielding effect provided by the residue silica ash formed in pyrolysis, excellent aging-resistant performance of polysilicone, outstanding smoke suppression ability, low mass density, nontoxicity, electrical insulating property, and so on [9]. Though silicone rubbers combust lower heat than other polymers, they are still flammable and ignitable. Therefore, inorganic flame retardants, such as $\mathrm{Al}(\mathrm{OH})_{3}$, red phosphorus, $\mathrm{Fe}_{2} \mathrm{O}_{3}$, and $\mathrm{SiO}_{2}$, are usually incorporated into silicone rubbers to fabricate fire-proof products $[10,11]$.

However, the synergetic effect between the polymer matrix and inorganic fire-retardant and the total performance of the composites are sometimes too intricate to evaluate. For example, some inorganic flame retardant additives themselves are controversial enough as the released toxic gas and smoke are extremely harmful despite the outstanding flame-retardant property [12]. Besides, the content of the inorganic filler as a function of fire retardant is limited by the chemical and physical property of the rubber matrix. Therefore, silane-modified polyether can be added to the 
TABLE 1: Composition of raw materials (unit: g).

\begin{tabular}{lcccccccccc}
\hline Sample & Vi-PDMS-Vi & PMVS & SMP & HO-PDMS-OH & Al(OH)3 & Silica & Carbon black & Polymerization inhibitor & PMHS & Pt-catalyst \\
\hline 1 & 15 & 15 & 20 & 70 & 80 & 2 & 0.5 & 0.9 & 45 & 0.5 \\
2 & 12.5 & 12.5 & 25 & 60 & 90 & 3 & 0.4 & 0.7 & 40 & 0.5 \\
3 & 10 & 10 & 30 & 50 & 110 & 4 & 0.2 & 0.5 & 30 & 0.5 \\
4 & 5 & 5 & 40 & 40 & 120 & 5 & 0.2 & 0.5 & 45 & 0.5 \\
\hline
\end{tabular}

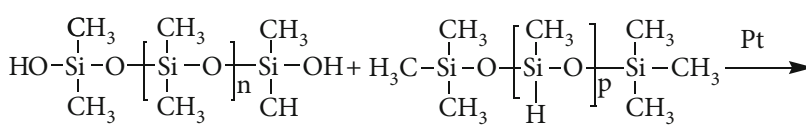

HO-PDMS-OH

PMHS

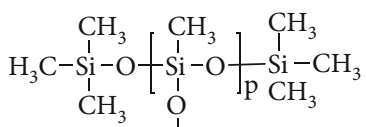

$$
\mathrm{H}_{3} \mathrm{C}-\mathrm{Si}-\mathrm{CH}_{3}
$$

$$
\begin{aligned}
& \mathrm{H}_{3} \mathrm{C}-\mathrm{Si}-\mathrm{CH}_{3}
\end{aligned}
$$

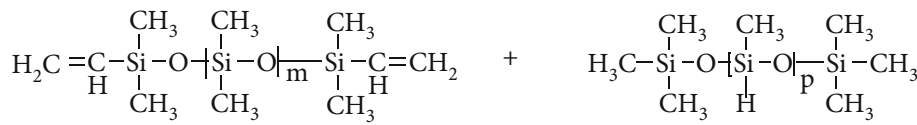$$
\mathrm{H}_{3} \mathrm{C}-\mathrm{Si}-\mathrm{CH}_{3}
$$$$
\stackrel{\mathrm{O}}{\mathrm{O}}
$$

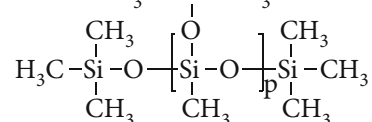

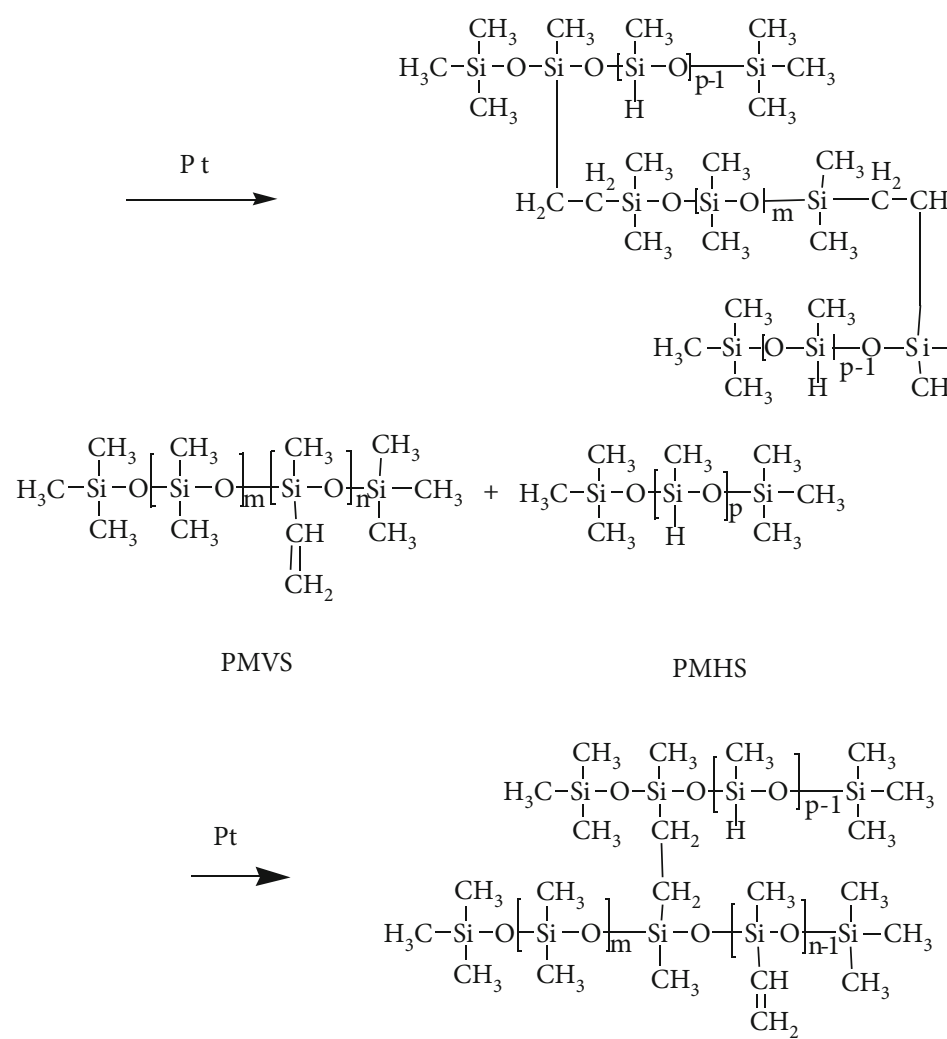

Figure 1: The foaming (up) and vulcanization reactions (middle and down). 
rubber matrix, as the low viscosity makes it possible to add more flame retardant additives.

The solidification reaction is difficult to control when non-reactive components are doped in the material. Herein, in this work, we presented the synthesis of fire-retardant room-temperature-vulcanized silicone rubber foam by a facial way, and aluminum hydroxide was incorporated as a flame retardant. The experiments were carried in a wide range of feed ratios, and the flame retardancy, compression stress-strain properties of the silicone rubber foams were systematically studied. These nontoxic, smokeless, and halogen-free silicone rubber foams can be applied as excellent fire-proof sealing materials.

\section{Experimental}

2.1. Materials. $\alpha, \omega$-dihydroxypolydimethylsiloxane (HOPDMS-OH, purity $\geq 98 \%$, viscosity $750 \mathrm{mPas}$, Shandong Dayi Chemical Co., Ltd.), divinylpolydimethylsiloxane (Vi-PDMS-Vi, purity $\geq 99 \%$, viscosity $3500 \mathrm{mPaS}$, vinyl content wt\% 0.43, Shandong Dayi Chemical Co., Ltd.), polymethylvinylsiloxane (PMVS, purity $\geq 99 \%$, viscosity $3500 \mathrm{mPa}$ s, vinyl content wt\% 0.7, Shandong Dayi Chemical Co., Ltd.), polymethylhydrosiloxane (PMHS, purity $\geq 98 \%$, viscosity $20 \mathrm{mPas}$, active hydrogen content wt $\%$ $\geq 1.5$, Shandong Dayi Chemical Co., Ltd.), and Silane modified polyether (SMP, viscosity $36000-42000 \mathrm{mPa}$, Risun Polymer) were purchased and used directly. Aluminum hydroxide $\left(\mathrm{Al}(\mathrm{OH})_{3}\right.$, Zhengzhou Beifang Aluminum Co., Ltd.) Silica (Wacker International Group Co., Ltd), platinum catalyst (Shandong Dayi Chemical Co., Ltd), and carbon black (Anyang Tongsheng Carbon Black Co., Ltd.) were used as additives.

2.2. Preparation of Silicone Foam Materials. Vi-PDMS-Vi and PMVS with a weight ratio of $1: 1$ were mixed first, and then, HO-PDMS-OH, SMP, PMHS, catalyst, polymerization inhibitor, and other dopants were added and stirred to form a homogenous mixture, with weight ratios shown in Table 1. The viscous liquids were kept still at room temperature in a proper mold until complete vulcanization was reached, and silicone foam materials were obtained. The vulcanization and foaming reactions are shown in Figure 1.

2.3. Characterization. The apparent densities of the silicone rubber were calculated by Equation (1), referring to ISO 845-2006:

$$
\rho=\frac{m}{V} \times 10^{6}
$$

where $m$ is the mass of the sample in grams, $V$ is the volume of the sample in cubic millimeters. Each sample was cut to a cubic with a size of $100 \mathrm{~mm} \times 100 \mathrm{~mm} \times 100 \mathrm{~mm}$, and the apparent density of each sample was decided by the average value of five specimens. The expansion ratios were calculated by the volume ratios of the silicone rub-

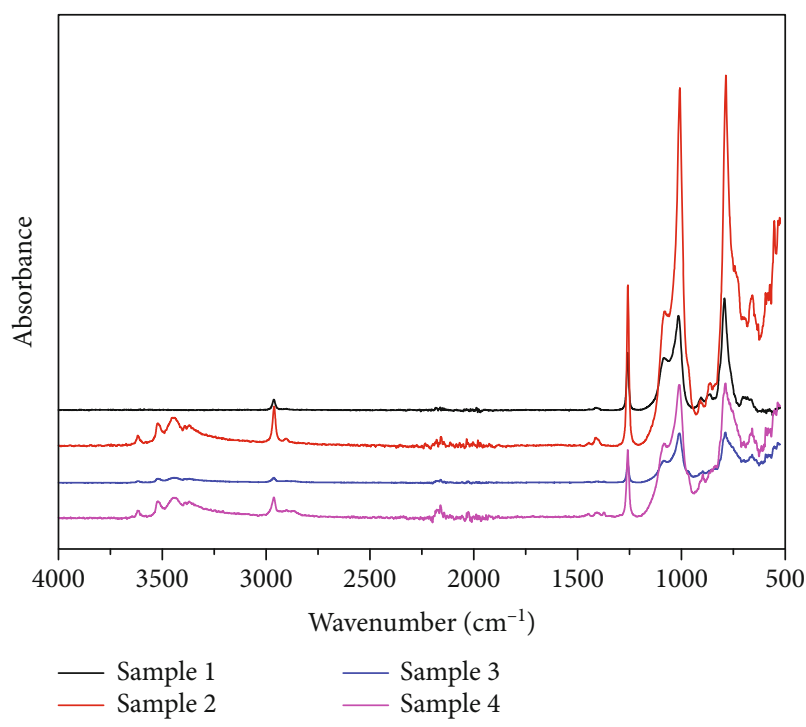

FIgURE 2: The ATR-FTIR spectra of the composite materials.

bers after and before the vulcanization reaction, according to Equation (2)

$$
\frac{V_{\mathrm{g}}-V_{\mathrm{i}}}{V_{\mathrm{g}}} \times 100
$$

where $V_{g}$ is the geometrical volume of the test specimen, $10 \mathrm{~mm} \times 10 \mathrm{~mm} \times 10 \mathrm{~mm}$, and $V_{i}$ is the volume of the tested specimen into which water cannot get in or out. To measure $V_{i}$, a certain amount of water was put into a graduated cylinder and recorded as $V_{1}$. Then, the specimen with a size of $10 \mathrm{~mm} \times 10 \mathrm{~mm} \times 10 \mathrm{~mm}$ was put immersed, and the total volume was recorded as $V_{2}$, so the $V_{i}=V_{2}-V_{1}$. The microstructure was studied with a field-emission scanning electron microscopy (ZEISS Merlin Compact).

The cell densities of the samples were tested with the following equation, referring to the literature $[13,14]$.

$$
N_{0}=\left[\frac{n M^{2}}{A}\right]^{\frac{3}{2}} \varphi
$$

where $n, M, A$, and $\phi$ represented the pore number in SEM image, the amplification factor, the area of SEM image, and the expansion ratio. The chemical structure of the silicone foams was investigated with ATR-FTIR, with a Nicolet IS 10 equipment in a wavenumber range of $4000-500 \mathrm{~cm}^{-1}$. The thermal stability of silicone foams was studied with a thermogravimetric analysis device (PerkinElmer, Pyris Diamond TG-DTA), from room temperature to $900^{\circ} \mathrm{C}$, at a ramp rate of $10^{\circ} \mathrm{C} \mathrm{min}^{-1}$, in the air. The stress-strain curves were measured with a universal testing machine (WAW/WEW1000D, Jinanshidai Testing Machine Co., Ltd.) and recorded according to GB/T 8168-2008. The size of the specimen was $100 \mathrm{~mm} \times 100 \mathrm{~mm} \times 25 \mathrm{~mm}$, and three specimens were tested for each sample with a preload of $2 \mathrm{~N}$. The load of 


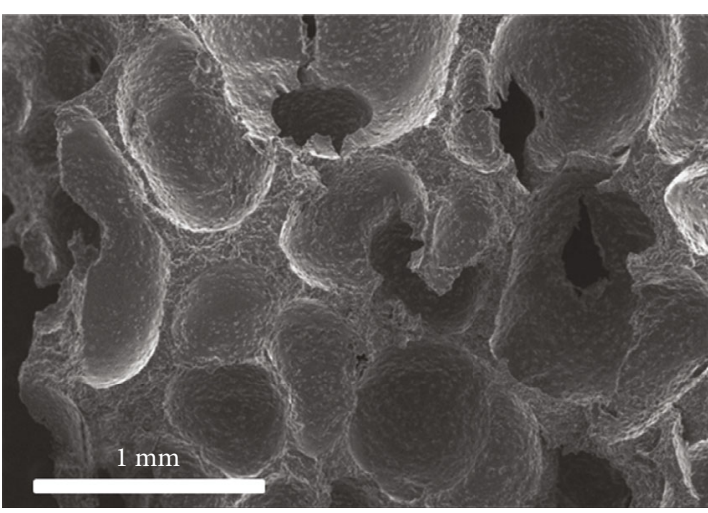

(a)

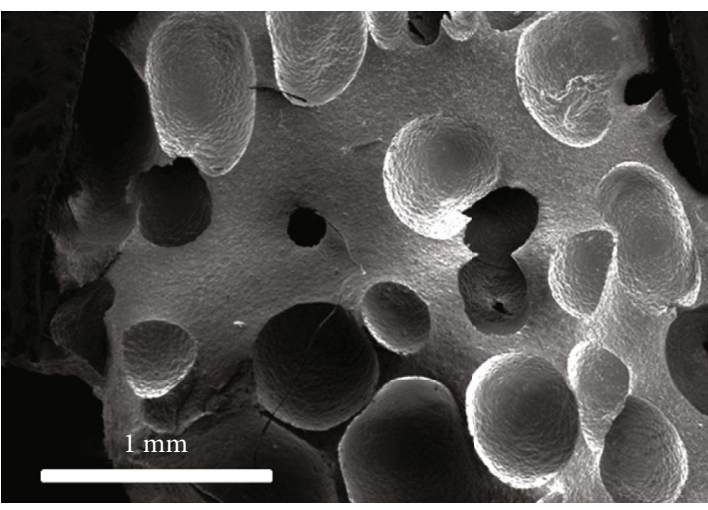

(c)

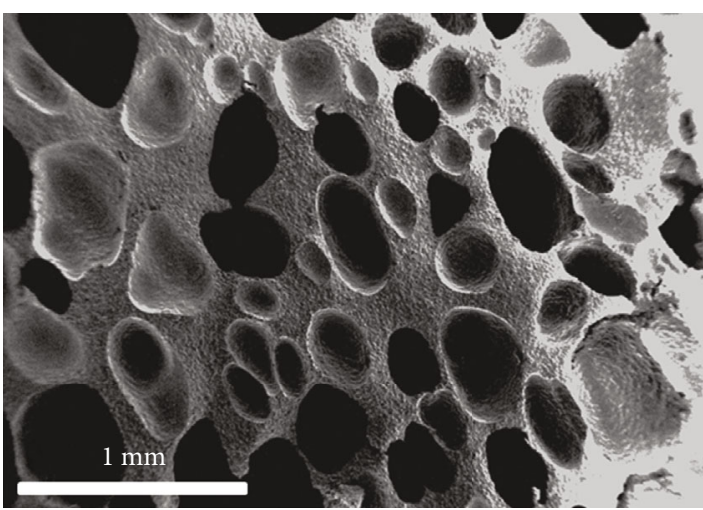

(b)

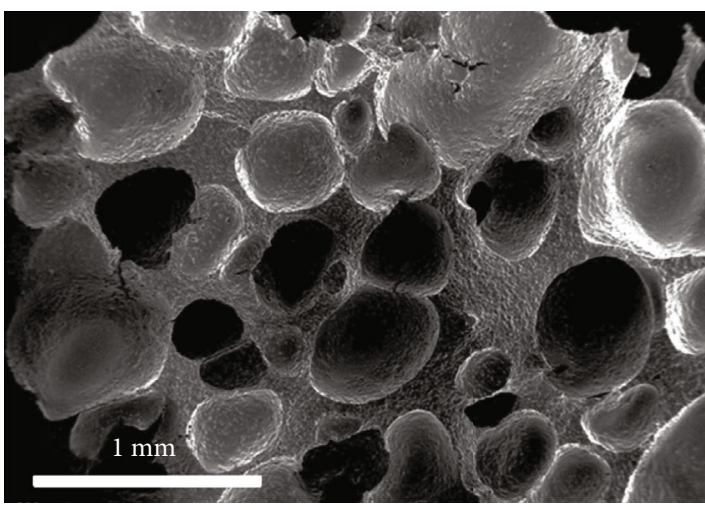

(d)

FIgURE 3: The SEM pictures of the composite materials. (a-d) Corresponding to Sample 1-4.

the compressing plate to the specimen was gradually increased along the thickness direction at a rate of $12 \mathrm{~mm} \mathrm{~min}^{-1}$ until the specimen was completely broken. The compressive strain was calculated by Equation (4)

$$
\varepsilon_{\alpha}=\frac{T-T_{\mathrm{i}}}{T},
$$

where $\varepsilon_{\alpha}$ is the compression deformation (\%), $T$ is the original height before compression, and $T_{\mathrm{i}}$ is the height after compression. And the compressive stress was calculated following the formula

$$
\sigma=\frac{P}{A} \times 10^{-6},
$$

where $\sigma$ is the press stress $(\mathrm{Pa}), P$ is the loaded force $(\mathrm{N})$, and $A$ is the base area of the specimen $\left(\mathrm{mm}^{-2}\right)$. The fireretardancy property of the composites was studied with the vertical burning tests according to the UL-94 method $[15,16]$, and the materials are classified as V0, V1, or V2. The specimens with a size of $125 \mathrm{~mm} \times 13 \mathrm{~mm} \times 1.6 \mathrm{~mm}$ were ignited with methane. 10 seconds later, the methane was removed and the first afterflame time for the specimen was recorded as $t_{1}$. Once the first afterflame is extinguished, the specimen was ignited again for another 10 seconds, and the second afterflame time $\left(t_{2}\right)$ and afterglow time $\left(t_{3}\right)$ were noted. A piece of cotton was placed under the specimen, and if the cotton was ignited by the burning drops, the results should be recorded.

\section{Results and Discussion}

3.1. Preparation of the Composite Materials. Samples were synthesized with vulcanization and foaming reactions at room temperature. As shown in Figure 1, vulcanization reactions between Vi-PDMS-Vi, PMVS, and PMHS cross-linked to form the skeleton of the composite material, and the reaction between HO-PDMS-OH and PMHS caused the foaming structure. After 72 hours, all the samples were solidified.

ATR-FTIR was carried out to study the chemical structures of the samples, and the results were shown in Figure 2. The peak at $3620 \mathrm{~cm}^{-1}$ was the signal of Si-OH bond of residual HO-PDMS-OH, and the multiple peaks near $3500 \mathrm{~cm}^{-1}$ were the signals of Si-OH bonds. In all four samples, $\mathrm{Si}-\mathrm{CH}=\mathrm{CH}_{2}$ bond around $1620 \mathrm{~cm}^{-1}$ was not detected, signifying the reactions were completed. The weak peak at $2150 \mathrm{~cm}^{-1}$ was the characteristic signal of $\mathrm{Si}-\mathrm{H}$, declaring the complete consumption of PMHS. The degree of vulcanization reaction affected the curing parameters of the rubber foam and the mechanical strength of the matrix. The strong peak at $1250 \mathrm{~cm}^{-1}$ was caused by the $\mathrm{Si}-\mathrm{CH}_{3}$, and the Si-O-C peaks appeared in the range of 1000 to $1080 \mathrm{~cm}^{-1}$ 


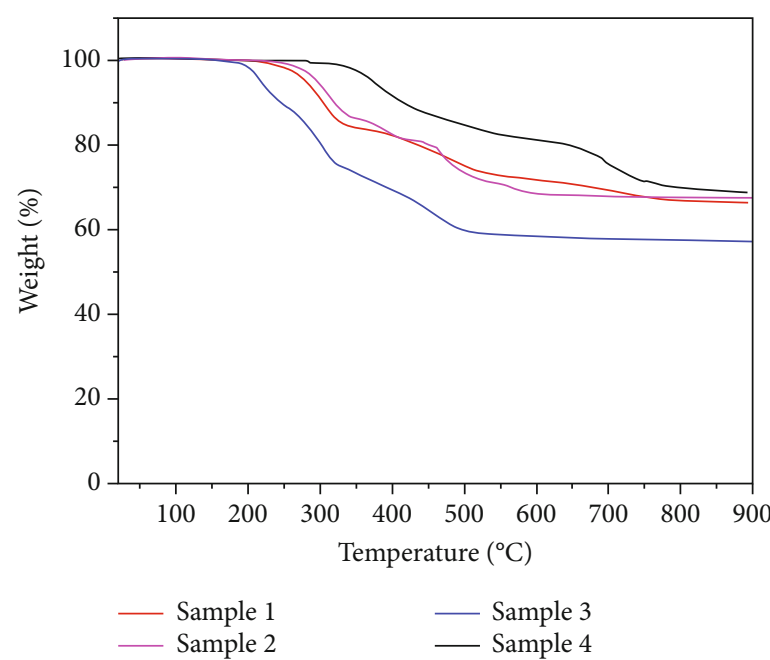

(a)

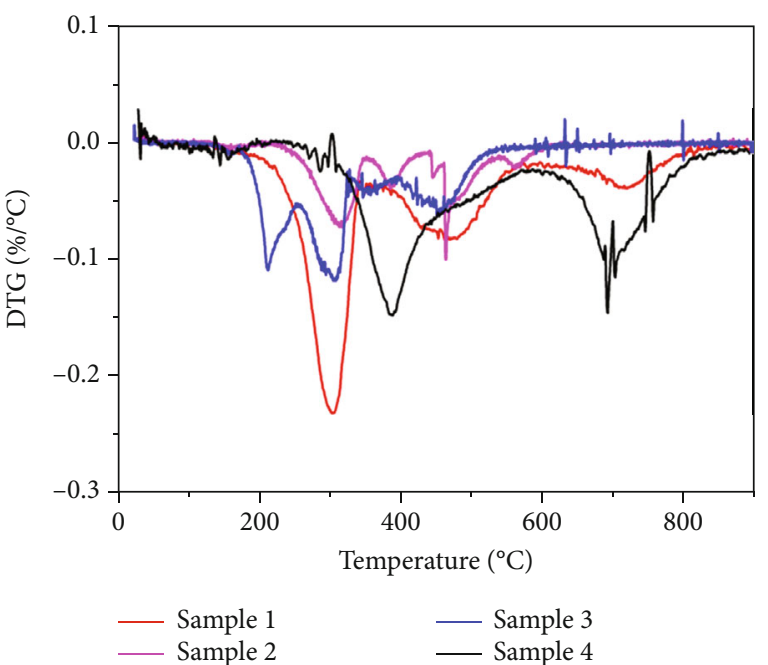

(b)

FIGURE 4: The thermogravimetry of the composite materials.

[17]. The ATR-FTIR results proved the samples were successfully synthesized.

The morphology of the prepared composite materials was recorded with SEM, as shown in Figure 3. The cell diameters of the four composite materials, formed in the foaming process, were close and in a range of $0.1-0.8 \mathrm{~mm}$. The contained additives were dispersed uniformly in the silicone rubber and caused the roughness of the cell wall. The cell structure ensured the silicone rubber high expansion ratios after vulcanization, as well as good stress-strain capacity, which was good for effective sealing.

3.2. Thermal Stability of the Composite Materials. The thermal stability of fire-proof sealing materials is essential, and thermogravimetry was applied to investigate the four samples, as shown in Figures 4(a) and (b). All samples experienced multistep decomposition reactions. The decomposition process of Sample 1 started from $280^{\circ} \mathrm{C}$, where the residual weight percent of Sample 1 was 95\%. The thermal stability of Sample 2 was close to Sample 1. The thermal stability of sample 3 was relatively poorer than the other three analogs, as the decomposition process started from $200^{\circ} \mathrm{C}$. The first degradation reaction of Sample 4 with a higher amount of $\mathrm{Al}(\mathrm{OH})_{3}$ started from $380^{\circ} \mathrm{C}$, which was $100^{\circ} \mathrm{C}$ higher than Sample 1. It can be found from the related TGA data (Figure 4(b)) that the peak temperatures of the first pyrolysis were 303 and $388^{\circ} \mathrm{C}$ for Sample 1 and Sample 4, respectively. The addition of $\mathrm{Al}(\mathrm{OH})_{3}$ increased the thermal stability of the silicone rubber, which was helpful for fireretardant materials. After decomposition, only $\mathrm{SiO}_{2}$ and $\mathrm{Al}_{2}$ $\mathrm{O}_{3}$ remained, and the left weight percentages of Sample 1-4 were $66 \%, 67 \%, 57 \%$, and $69 \%$, respectively. The left nonflammable $\mathrm{SiO}_{2}$ and $\mathrm{Al}_{2} \mathrm{O}_{3}$ can act as shielding to stop the fire from spreading, which was the advantage of silicone rubber-based fire-retardant composite materials. The residue increment of Sample 2-4 comparing to Sample 1 was caused by the added amount of inorganic component $\mathrm{Al}(\mathrm{OH})_{3}$.
TABle 2: Properties of the prepared composite materials.

\begin{tabular}{lcccc}
\hline Sample & 1 & 2 & 3 & 4 \\
\hline Apparent density $\left(\mathrm{g} \mathrm{cm}^{-3}\right)$ & 0.473 & 0.456 & 0.483 & 0.465 \\
Expansion ratio & 2.73 & 2.76 & 2.79 & 2.77 \\
Porosity (\%) & 56.34 & 57.62 & 56.73 & 55.78 \\
\hline
\end{tabular}

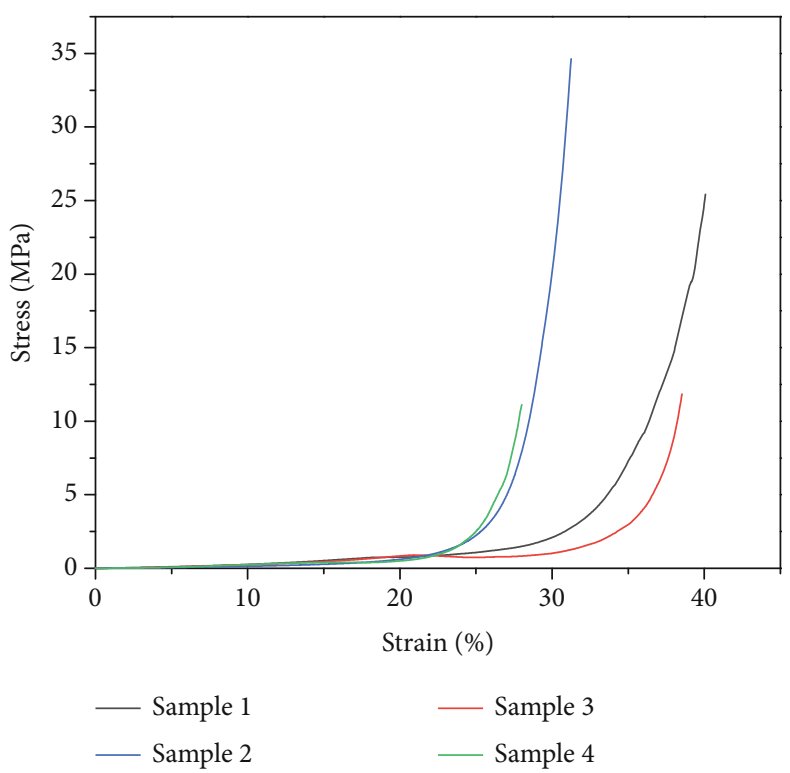

FIgURE 5: Stress-strain curves of the composite materials.

3.3. Mechanical Properties of the Composite Materials. The mechanical properties of the composite materials are crucial to the application of fire-retardant materials, and the apparent densities, expansion ratios, and porosities of the composite materials are shown in Table 2. The values of apparent 


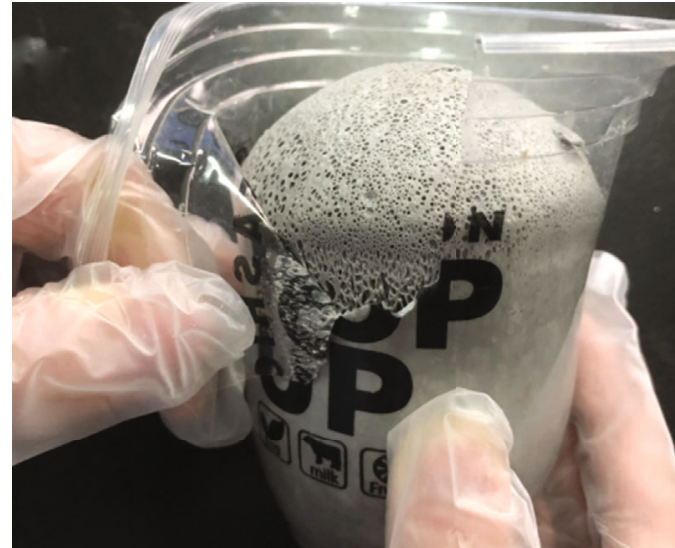

(a)

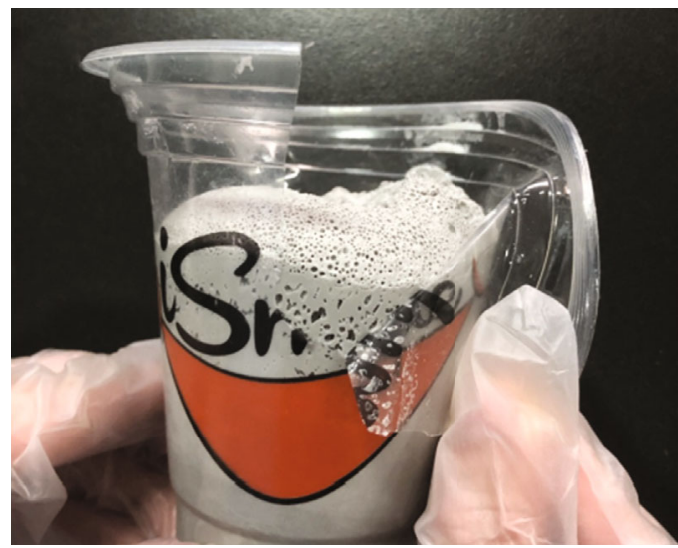

(c)

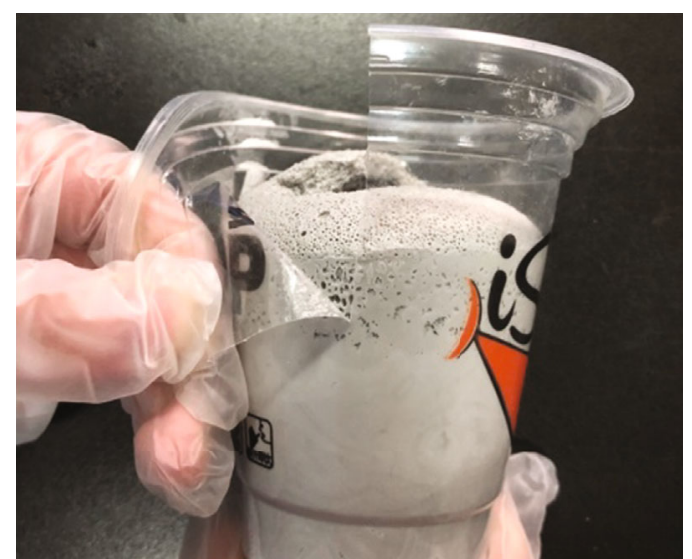

(b)

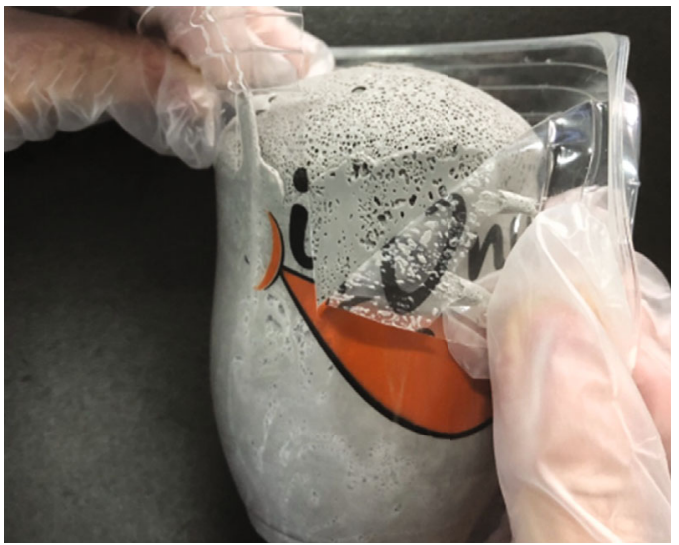

(d)

Figure 6: Optical images of the composite materials.

densities ranged from 0.456 to $0.483 \mathrm{~g} \mathrm{~cm}^{-3}$, and the discrepancy was inconspicuous. The measured expansion ratios were between 2.73 and 2.79 , endowing the composites as sealing materials for the holes and cracks. The calculated cell densities of the four samples were $1.7 \times 10^{9}, 2.9 \times 10^{9}$, $1.2 \times 10^{9}$, and $1.9 \times 10^{9}$ pores per $\mathrm{cm}^{3}$. The size of pores was not evenly distributed. These data indicated that the silicone rubber foam can be successfully synthesized within a wide range of feed ratios.

The stress-strain curves of the composite materials were recorded with a universal testing machine, as presented in Figure 5. The results were consistent with the mode of conventional foams proposed by Gibson and Ashby [18, 19]. As the strain increased from zero to a certain value, the stress-strain relationships were approximately linear, and the rising trends of stress were gradual and smooth. The flat trends can be caused by the bending of cell walls or the minimum collapse of foam structure, corresponding to the compressive elastic region. Then, the stress increased sharply with the strain, due to the massive collapse of the cell structure. For Sample 1-4, the starting strains where the foam structure began to collapse were $28 \%, 23 \%, 32 \%$, and $22 \%$, respectively. The four samples displayed good endurance to the stress, which is useful since the foaming materials should resist the consequential mechanical stress of the heat runaway and blasts of airflow.

When the foaming composites are used as fireproof sealing materials, their adhesive performance to the surface of other materials is also essential, especially for the plastic materials. However, the surface energy of routine silicone rubber is low, so generally, the adhesion of routine silicone rubber is poor. In practical application, the sealing materials should adhere to the walls and gaps of plastic or metal pipes as long as possible. The adhesive performance of the samples to the surface of the commercial plastic cups is shown in Figure 6. After pealling off, the attachment remained on the inner walls of plastic walls, declaring the stickness of the composites to the plastic materials. Therefore, the samples are applicable for fireproof sealing materials.

\subsection{Fire-Retardant Properties of the Composite Materials.} The UL-94 tests of the composite materials are listed in Table 3. Firstly, the afterflame time $\left(t_{1}\right.$ or $\left.t_{2}\right)$ for each individual specimen was less than 10 seconds. Secondly, the total afterflame time $\left(t_{1}+t_{2}\right)$ for any condition set for each specimen was less than $50 \mathrm{~s}$. Thirdly, the afterflame plus afterglow time for each specimen after the second flame application was less than $30 \mathrm{~s}$. Meanwhile, afterflame or afterglow of 
TABLE 3: Flame retardant test results.

\begin{tabular}{|c|c|c|c|c|c|c|c|c|c|}
\hline & Specimen & $t_{1}$ & $t_{2}$ & $t_{3}$ & $\mathrm{t}_{1}+\mathrm{t}_{2}$ & $t_{2}+t_{3}$ & $\begin{array}{l}\text { Afterflame or afterglow to } \\
\text { the holding clamp }\end{array}$ & $\begin{array}{c}\text { Cotton ignited by } \\
\text { burning drops }\end{array}$ & UL-94 rate \\
\hline \multirow{5}{*}{ Sample 1} & 1 & 5 & 4 & 15 & 9 & 19 & No & No & \multirow{5}{*}{ V0 } \\
\hline & 2 & 5 & 5 & 14 & 10 & 19 & No & No & \\
\hline & 3 & 6 & 4 & 15 & 10 & 19 & No & No & \\
\hline & 4 & 5 & 3 & 14 & 8 & 17 & No & No & \\
\hline & 5 & 6 & 5 & 14 & 11 & 19 & No & No & \\
\hline \multirow{5}{*}{ Sample 2} & 1 & 4 & 5 & 14 & 9 & 19 & No & No & \multirow{5}{*}{ V0 } \\
\hline & 2 & 5 & 5 & 14 & 10 & 19 & No & No & \\
\hline & 3 & 5 & 4 & 13 & 9 & 17 & No & No & \\
\hline & 4 & 4 & 4 & 13 & 8 & 17 & No & No & \\
\hline & 5 & 5 & 4 & 13 & 9 & 17 & No & No & \\
\hline \multirow{5}{*}{ Sample 3} & 1 & 4 & 4 & 13 & 8 & 17 & No & No & \multirow{5}{*}{ V0 } \\
\hline & 2 & 5 & 4 & 13 & 9 & 17 & No & No & \\
\hline & 3 & 4 & 4 & 12 & 8 & 16 & No & No & \\
\hline & 4 & 4 & 4 & 13 & 8 & 17 & No & No & \\
\hline & 5 & 4 & 5 & 11 & 9 & 16 & No & No & \\
\hline \multirow{5}{*}{ Sample 4} & 1 & 3 & 3 & 12 & 6 & 15 & No & No & \multirow{5}{*}{ V0 } \\
\hline & 2 & 3 & 4 & 12 & 7 & 16 & No & No & \\
\hline & 3 & 4 & 4 & 11 & 8 & 15 & No & No & \\
\hline & 4 & 4 & 3 & 12 & 7 & 15 & No & No & \\
\hline & 5 & 3 & 4 & 11 & 7 & 15 & No & No & \\
\hline
\end{tabular}

any specimen up to the holding clamp was not observed, nor the cotton indicator was ignited by flaming particles or drops. Therefore, all samples were rating in V0 $[15,16,20]$. The excellent fire-retardant properties were endowed by the synergetic effect of silicone rubber and the fire-retardant additives and ensured the composite materials practical application foreground in fireproof sealing.

\section{Conclusion}

In this work, a series of silicone rubber foam was prepared through room temperature vulcanization and foaming. The characterization results proved that the composite materials had been successfully synthesized in a wide range of feed ratios, and the cell structures and other mechanical properties were suitable for fire-retarding application. The composite materials exhibited excellent thermal stability. Fire-retardant tests proved the outstanding fireproof property for all four samples. In summary, the composite materials displayed good overall performance as fireretardant materials.

\section{Data Availability}

All data and models generated or used during the study appear in the submitted article.

\section{Conflicts of Interest}

The authors declare that they have no conflicts of interest.

\section{References}

[1] M. Imiela, R. Anyszka, D. M. Bieliński, M. Lipińska, P. Rybiński, and B. Syrek, "Synergistic effect of mica, glass frit, and melamine cyanurate for improving fire resistance of styrene-butadiene rubber composites destined for ceramizable coatings," Coatings, vol. 9, no. 3, p. 170, 2019.

[2] N. F. Attia and B. K. Saleh, "Novel synthesis of renewable and green flame-retardant, antibacterial and reinforcement material for styrene-butadiene rubber nanocomposites," Journal of Thermal Analysis and Calorimetry, vol. 139, no. 3, pp. 1817-1827, 2020.

[3] A. Abdel-Hakim, T. M. El-Basheer, and A. Abdelkhalik, "Mechanical, acoustical and flammability properties of SBR and SBR-PU foam layered structure," Polymer Testing, vol. 88, p. 106536, 2020.

[4] P. Intharapat, C. Nakason, and A. Kongnoo, "Preparation of boric acid supported natural rubber as a reactive flame retardant and its properties," Polymer Degradation and Stability, vol. 128, pp. 217-227, 2016.

[5] N. Wang, G. Xu, Y. Wu et al., "The influence of expandable graphite on double-layered microcapsules in intumescent flame-retardant natural rubber composites," Journal of Thermal Analysis and Calorimetry, vol. 123, no. 2, pp. 1239-1251, 2016. 
[6] Z. E. Sun and Y. Zhou, "Discussion on fire-proof sealing technology and product," Procedia Engineering, vol. 135, pp. 644-648, 2016.

[7] G. Camino, L. Costa, and M. P. L. di Cortemiglia, "Overview of fire retardant mechanisms," Polymer Degradation and Stability, vol. 33, no. 2, pp. 131-154, 1991.

[8] C. Zhu, C. Deng, J. Y. Cao, and Y. Z. Wang, "An efficient flame retardant for silicone rubber: preparation and application," Polymer Degradation and Stability, vol. 121, pp. 42-50, 2015.

[9] F. Lou, W. Yan, W. Guo, T. Wei, and Q. Li, "Preparation and properties of ceramifiable flame-retarded silicone rubber composites," Journal of Thermal Analysis and Calorimetry, vol. 130, no. 2, pp. 813-821, 2017.

[10] A. U. R. Shah, M. N. Prabhakar, and J.-I. Song, "Current advances in the fire retardancy of natural fiber and bio-based composites - a review," International Journal of Precision Engineering and Manufacturing-Green Technology, vol. 4, no. 2, pp. 247-262, 2017.

[11] E. Gallo, B. Schartel, U. Braun, P. Russo, and D. Acierno, "Fire retardant synergisms between nanometric $\mathrm{Fe} 2 \mathrm{O} 3$ and aluminum phosphinate in poly(butylene terephthalate)," Polymers for Advanced Technologies, vol. 22, no. 12, pp. 2382-2391, 2011.

[12] Y. Shi, B. Yu, Y. Zheng et al., "A combination of POSS and polyphosphazene for reducing fire hazards of epoxy resin," Polymers for Advanced Technologies, vol. 29, no. 4, pp. 12421254, 2018.

[13] D. Yin, J. Mi, H. Zhou, X. Wang, and H. Tian, "Fabrication of branching poly (butylene succinate)/cellulose nanocrystal foams with exceptional thermal insulation," Carbohydrate Polymers, vol. 247, p. 116708, 2020.

[14] Y. Li, D. Yin, W. Liu, H. Zhou, Y. Zhang, and X. Wang, "Fabrication of biodegradable poly (lactic acid)/carbon nanotube nanocomposite foams: significant improvement on rheological property and foamability," International Journal of Biological Macromolecules, vol. 163, pp. 1175-1186, 2020.

[15] M. A. de Freitas Rocha, A. Landesmann, S. P. da Silva Ribeiro, and R. C. Martins, "Enhancement of fire retardancy properties of glass fibre-reinforced polyesters composites," Fire and Materials, vol. 43, no. 6, pp. 734-746, 2019.

[16] UL 94-Standard for Tests for Flammability of Plastic Materials for Parts in Devices and Appliances, Underwriter Laboratories, 2013.

[17] Y. Tan, J. Yao, and H. Zhu, "Preparation of room temperature vulcanized silicone rubber foam/SiO2 nanocomposite and its fatigue buffering performance," Journal of Macromolecular Science, Part A Pure and Applied Chemistry, vol. 57, no. 12, pp. 844-853, 2020.

[18] B. Xiang, Y. Jia, Y. Lei et al., "Mechanical properties of microcellular and nanocellular silicone rubber foams obtained by supercritical carbon dioxide," Polymer Journal, vol. 51, no. 6, pp. 559-568, 2019.

[19] L. J. Gibson and M. F. Ashby, Cellular Solids: Structure and Properties, Cambridge University Press, Cambridge, UK, 1997.

[20] W. Chen, C. Xu, Y. Liu, Y. Liu, and Q. Wang, "Synthesis and properties of an intrinsic flame retardant silicone rubber containing phosphaphenanthrene structure," RSC Advances, vol. 7, no. 63, pp. 39786-39795, 2017. 